Vol. 2, n. 3 - Edição Especial: Ciclos Formativos em Ensino de Ciências.

\title{
Jogos Didáticos como Instrumentos de Ensino
}

\section{Didactic Games as a Teaching Instrument}

Daniel Augusto Colombo (colomboodaniel@mail.com)

Universidade Federal da Fronteira Sul - UFFS

Resumo: O presente artigo relata a experiência proporcionada pelo Programa Institucional de Bolsas de Iniciação à Docência, (PIBID), onde aplicou-se um jogo didático em uma turma de primeiro ano do Ensino Médio, no componente curricular Física, em escola pública estadual localizada em Cerro Largo, Rio Grande do Sul. Objetivou-se uma melhora no engajamento da turma em relação aos objetos de conhecimento, agindo como facilitadora e mediadora de discussões a fim de se atingir um bom entendimento conceitual e matemático dos conceitos físicos abordados.

Palavras-chave: Jogo didático; Educação; Ensino de Física; Ensino de Ciências.

Abstract: This article describes an experience provided by the Institutional Teaching Initiation Scholarship Program, in Portuguese known by the name "Programa Institucional de Bolsas de Iniciação à Docência, PIBID), where a didactic game was applied in a first grade high school Physics class, of a state school located in the city of Cerro Largo, Rio Grande do Sul, Brazil. The objective was to improve the class's engagement with the objects of knowledge, acting as facilitator and mediator of discussions in order to achieve a good conceptual and mathematical understanding of the approached physical concepts.

Keywords: Didactic game; Education; Physics teaching; Science teaching.

\section{INTRODUÇÃO}

Visando antecipar o vínculo entre os futuros professores e as salas de aula da rede pública, o PIBID faz uma articulação entre a educação superior (por meio das licenciaturas), a escola e os sistemas estaduais e municipais. Para a grande maioria dos alunos bolsistas, o PIBID se torna o primeiro contato do indivíduo na posição da docência nas escolas públicas, tanto no ensino fundamental como no médio. O relato abordado, consiste na primeira experiência docente de um grupo de bolsistas durante o programa.

Buscando os referenciais estudados durante a formação como professor, ainda que em andamento, notou-se que a utilização dos jogos didáticos seria uma boa abordagem inicial. Principalmente percebendo a comunicação como uma característica própria do indivíduo, responsável pelo desenvolvimento linguístico e cognitivo do aluno, geradora 
Vol. 2, n. 3 - Edição Especial: Ciclos Formativos em Ensino de Ciências.

da capacidade de interagir socialmente, tanto na escola, quanto no ambiente social no qual está inserido, fazendo assim a dinâmica comunicativa dos jogos didáticos essências para o engajamento e facilitação da compreensão dos conhecimentos científicos.

\section{DESCRIÇÃO DAS ATIVIDADES}

Durante o programa PIBID o grupo de bolsistas pelo curso de Física Licenciatura da Universidade Federal da Fronteira Sul, composto por cinco integrantes, planejou e elaborou material para a aplicação de um jogo didático. O jogo em questão foi aplicado em uma turma de primeiro ano do Ensino Médio constituída por aproximadamente vinte alunos, na Escola Estadual De Educação Básica Eugênio Frantz em Cerro Largo -RS.

O jogo foi nomeado como "Truco Científico", assim os grupos previamente divididos deveriam disputar pontos respondendo perguntas de múltipla escolha. Apresenta-se a pergunta e os grupos trabalham internamente em conjunto, o grupo que conseguir responder primeiro, sinalizando com uma buzina, obterá vantagem caso acerte. O primeiro grupo a buzinar ganha três pontos caso acerte, caso erre perderá três pontos. O segundo grupo a sinalizar ganha dois pontos caso acerte e perde dois pontos se errar. Já o último grupo a responder ganhará apenas um ponto se acertar, e perderá o mesmo se errar. Lembra-se que as regras referentes à pontuação podem ser alteradas conforme o número de alunos.

Outra regra pertinente à pontuação consiste na atribuição de um recurso chamado "Justifique" para cada grupo. O "Justifique" consiste na possibilidade de um grupo pedir para outro justificar a resposta, mediante ao juízo do professor, o grupo que conseguir justificar corretamente dobrará a pontuação alcançada na rodada, caso não consiga, os pontos irão para o grupo que pediu a justificativa. Nota-se que os grupos podem utilizar somente uma vez o recurso.

As perguntas (Quadro 1) foram elaboradas pelos bolsistas de acordo com os conceitos que a professora supervisora estava abordando no trimestre. Preparou-se dez questões para serem usadas em um total de cinquenta minutos. As perguntas fazem referência aos conceitos de Massa, Peso, Força, Aceleração, Movimentos Retilíneos e Lançamento Horizontal. 
Vol. 2, n. 3 - Edição Especial: Ciclos Formativos em Ensino de Ciências.

É importante ressaltar que o jogo didático confeccionado não se coloca como ponto de partida no processo de ensino e aprendizagem, o intuído projetado pelo grupo designava a atividade como um estímulo engajador nos estudantes quanto à conteúdos que foram previamente trabalhados.

\section{INIBIÇÃO SOCIAL NO CONTEXTO ESCOLAR}

Uma das maiores dificuldades enfrentadas pelos bolsistas, durante esta curta oportunidade para aplicação da atividade pedagógica, foi a aparente falta de envolvimento dos estudantes, principalmente nos contatos iniciais. Várias hipóteses podem ser levantadas acerca do porquê da falta de envolvimento: Falta de interesse pelos assuntos referenciados nas aulas, a dificuldade de participação quando há falta de conhecimento prévio dos assuntos trabalhados ou uma inibição social causada pela timidez.

Em um primeiro momento houve até mesmo dificuldade para organizar grupos na sala de aula, aparentava-se uma dificuldade de comunicação e socialização entre os colegas, geralmente organizando-se em grupos fechados e com poucas pessoas. No momento em que houve a exposição das perguntas os grupos aparentavam hesitantes na apresentação de suas respostas. O recurso descrito na seção anterior chamado "Justifique", onde há a possibilidade de um grupo pedir para outro justificar a resposta, praticamente não foi explorada pelos alunos, somente na última questão um grupo utilizou.

O comportamento da grande maioria dos estudantes remete à definição dos sintomas da timidez por Albisseti (1998), onde afirma que a timidez se manifesta em sintomas como: medo das pessoas, medo dos convites, medo de falar, medo de enrubescer, enfim, todos os medos que tendem a reduzir o contato com as pessoas e que trazem o isolamento.

O medo, a insegurança a inibição e o isolamento social conferem uma grande dificuldade no processo de ensino e aprendizagem. Se por um lado torna-se complexa a verificação da aprendizagem do aluno pelo educando, por outro, se desfavorece o processo de desenvolvimento do aluno visto que as relações interpessoais no processo de 


\section{Vol. 2, n. 3 - Edição Especial: Ciclos Formativos em Ensino de Ciências.}

aprendizado são fundamentais. Um alunado que necessite fazer uma pergunta, apresentar uma tarefa ou dialogar com os colegas e professor, terá dificuldade, isso porque a pessoa tímida tende a ter preocupação excessiva de errar.

Nenhuma forma de comportamento é tão forte quanto aquela ligada a uma emoção. Por isso, se quisermos suscitar no aluno as formas de comportamento de que necessitamos teremos sempre de nos preocupar com que essas reações deixem um vestígio emocional nesse alunado. (VYGOTSKY, 2001, p. 143)

A relação aluno-professor nessas situações faz-se de extrema importância para o contexto escolar. Na condição de que as interações estabelecem intervenções consideráveis no desenvolvimento do ser, tem-se a possibilidade de que o professor ajude na formação de alunos menos tímidos e mais seguros.

\section{A LUDICIDADE COMO INSTRUMENTO DE APRENDIZAGEM}

Durante o decorrer da aplicação do jogo didático, conforme descrito nas seções anteriores, houve uma significativa melhora na socialização e participação dos alunos na atividade. O contexto lúdico da atividade, à medida que se caracterizou como uma competição, havendo a promessa pela professora supervisora de "pontos extras" na média, estimulou a participação dos alunos, aflorando um senso de ludicidade não só como uma brincadeira, mas, principalmente como uma necessidade humana.

O desenvolvimento do aspecto lúdico facilita a aprendizagem, o desenvolvimento pessoal, social e cultural, colabora para a saúde mental, prepara para um estado interior fértil, facilita os processos de socialização, comunicação, expressão e construção do conhecimento (SANTOS, 1997).

Os jogos didáticos acabam por estabelecer uma dinâmica mais complexa entre professor e aluno. Se tratando de uma aprendizagem que não se define pela formatação das respostas bem definidas, e sim um exame do aluno em seu contexto integral, mantendo com maior facilidade com diálogo constante nas relações em sala de aula. Os jogos lúdicos nas disciplinas de ciências especificamente, facilitam a compreensão da natureza como um todo dinâmico e como um conjunto complexo de seres e ambientes, incluindo o homem, dessa forma torna-se claro e real a compressão e emprego dos conceitos científicos. 


\begin{abstract}
Muitos aspectos podem ser trabalhados por meio da confecção e da aplicação de jogos selecionados, com objetivos como: aprender a lidar com a ansiedade; refletir sobre limites; estimular a autonomia; desenvolver e aprimorar as funções neurossensoriomotoras; desenvolver a atenção e a concentração; ampliar a elaboração de estratégias; estimular o raciocínio lógico e a criatividade (RAU, 2007)
\end{abstract}

\title{
5. CONCLUSÃO
}

Ainda que em um espaço curto de tempo, o papel educativo do jogo foi facilmente observado durante sua aplicação com os alunos do primeiro ano do Ensino Médio. Notase que a construção de um espaço lúdico no contexto escolar favorece a criação de um ambiente mais dialogável, favorecendo a aquisição e retenção de conhecimentos.

Sobretudo por unir os aspectos lúdicos aos cognitivos, entende-se que o jogo é uma importante ferramenta para o ensino e aprendizagem de conceitos abstratos e complexos, impulsionado a motivação do aluno, o raciocínio, a argumentação. O ambiente incomum, infelizmente ainda pouco utilizado pela maioria dos professores, favorece o aluno a aprender a lidar com a ansiedade e a socializar melhorando o vocabulário e se tornando mais independentes.

\section{REFERÊNCIAS}

ALBISSETTI, Valério. 1998. Pode-se vencer a timidez? São Paulo: Paulinas.

RAU, M. C. T. D. A ludicidade na educação: uma atitude pedagógica. Curitiba: Ibpex, 2007.

SANTOS, S, M. P. dos. (org). Brinquedoteca: o lúdico em diferentes contextos. Rio de Janeiro: Vozes, 1997.

VYGOTSKY, Lev S. A formação social da mente. São Paulo: Martins Fontes, 1991

\section{ANEXOS}

Quadro 1 - Perguntas elaboradas para o jogo didático.

\begin{tabular}{|c|c|}
\hline $\begin{array}{l}\text { 1) A média das velocidades de um automóvel em } \\
\text { uma estrada, corresponde à sua velocidade } \\
\text { média? }\end{array}$ & $\begin{array}{l}\text { a) Sim, pois a velocidade média depende apenas da } \\
\text { variação das velocidades em um determinado } \\
\text { espaço de tempo. } \\
\text { b) Indiferente, pois a velocidade média pode ser } \\
\text { calculada pela média das velocidades e também }\end{array}$ \\
\hline
\end{tabular}


Vol. 2, n. 3 - Edição Especial: Ciclos Formativos em Ensino de Ciências.

\begin{tabular}{|c|c|}
\hline & $\begin{array}{l}\text { pela variação da distância em função da variação do } \\
\text { tempo. } \\
\text { c) Não, pois a velocidade média pode apenas ser } \\
\text { calculada pela variação da distância em função da } \\
\text { variação do tempo. }\end{array}$ \\
\hline $\begin{array}{l}\text { 2) Qual dos seguintes movimentos é considerado } \\
\text { um movimento uniforme? }\end{array}$ & $\begin{array}{l}\text { a) A chuva. } \\
\text { b) As hélices de um ventilador ligado após } 5 \\
\text { segundos. } \\
\text { c) Um carro em uma estrada com curva. }\end{array}$ \\
\hline $\begin{array}{l}\text { 3) O que significa dizer que a distância é } \\
\text { diretamente proporcional ao quadrado do } \\
\text { tempo? }\end{array}$ & $\begin{array}{l}\text { a) Velocidade média. } \\
\text { b) Velocidade instantânea. } \\
\text { c) Aceleração. }\end{array}$ \\
\hline 4) O que pesa mais? & $\begin{array}{l}\text { a) } 1 \mathrm{~kg} \text { de algodão na Terra. } \\
\text { b) } 1 \mathrm{~kg} \text { de chumbo na Lua. } \\
\text { c) Os dois anteriores pesam o mesmo. }\end{array}$ \\
\hline \begin{tabular}{llllr} 
5) Uma & pessoa andando & \multicolumn{2}{c}{ normalmente, } \\
desenvolve uma velocidade de $2 \mathrm{~m} / \mathrm{s}$. Que & Quá \\
distância percorrerá andando & durante 25 \\
minutos? & & & & \\
\end{tabular} & $\begin{array}{l}\text { a) } 0,3 \mathrm{~m} \\
\text { b) } 3 \mathrm{~km} \\
\text { c) } 30 \mathrm{dm}\end{array}$ \\
\hline $\begin{array}{l}\text { D) Durante certo intervalo de tempo o } \\
\text { velocímetro de um carro marca constantemente } \\
80 \mathrm{~km} / \mathrm{h} \text {. Isto indica que? }\end{array}$ & $\begin{array}{l}\text { a) A velocidade escalar instantânea é constante. } \\
\text { b) A velocidade escalar instantânea não é constante. } \\
\text { c) A velocidade média é constante. }\end{array}$ \\
\hline $\begin{array}{l}\text { 7) Um carro está em movimento com três pessoas } \\
\text { a bordo. o carro para bruscamente, a situação } \\
\text { que ocorre com as três pessoas se encaixa em } \\
\text { qual das seguintes leis da física? }\end{array}$ & $\begin{array}{l}\text { a) A primeira Lei de Newton. } \\
\text { b) A segunda Lei de Newton. } \\
\text { c) A terceira Lei de Newton. }\end{array}$ \\
\hline $\begin{array}{l}\text { 8) Toda força aplicada a um corpo tem uma } \\
\text { resultante de }\end{array}$ & $\begin{array}{l}\text { a) Sentido igual, intensidade igual e direção oposta. } \\
\text { b) Direção igual, intensidade igual e sentido oposto. } \\
\text { c) Sentido igual, direção igual e intensidade oposta. }\end{array}$ \\
\hline $\begin{array}{l}\text { 9) No instante em que um rifle posicionado na } \\
\text { horizontal é disparado, um objeto que está em } \\
\text { repouso mantido ao lado do rifle, é solto. Qual } \\
\text { objeto chega primeiro no chão? despreze o atrito } \\
\text { do ar. }\end{array}$ & $\begin{array}{l}\text { a) O projétil do rifle. } \\
\text { b) O objeto solto. } \\
\text { c) Os dois chegam ao mesmo tempo. }\end{array}$ \\
\hline $\begin{array}{l}\text { 10) O peso de um objeto na Lua é igual a um } \\
\text { sexto do seu peso na Terra. Considere este objeto } \\
\text { movendo-se com velocidade V na Terra e } \\
\text { movendo-se com a mesma velocidade V na Lua. } \\
\text { Qual a razão entre a energia cinética do corpo na } \\
\text { Terra e a energia cinética do corpo na Lua? }\end{array}$ & $\begin{array}{l}\text { a) } 1 \\
\text { b) } 1 / 6 \\
\text { c) } 6\end{array}$ \\
\hline
\end{tabular}

